\title{
Lignin Quantification of Papyri by TGA-Not a Good Idea
}

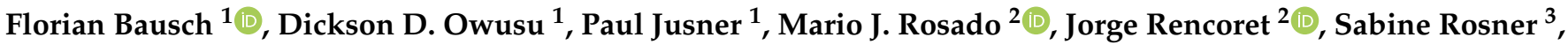

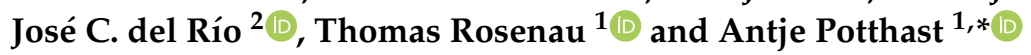

1 Department of Chemistry, Institute of Chemistry for Renewable Resources, University of Natural Resources and Life Sciences Vienna (BOKU), Konrad-Lorenz-Straße 24, A-3430 Tulln, Austria; florian.bausch@boku.ac.at (F.B.); dickson.owusu@boku.ac.at (D.D.O.); paul.jusner@boku.ac.at (P.J.); thomas.rosenau@boku.ac.at (T.R.)

2 Instituto de Recursos Naturales y Agrobiología de Sevilla, CSIC, Avenida Reina Mercedes, 10, E-41012 Seville, Spain; m.rosado@irnas.csic.es (M.J.R.); jrencoret@irnase.csic.es (J.R.); delrio@irnase.csic.es (J.C.d.R.)

3 Department of Integrative Biology and Biodiversity Research, Institute of Botany, University of Natural Resources and Life Sciences Vienna (BOKU), Gregor-Mendel Straße 33, A-1180 Vienna, Austria; sabine.rosner@boku.ac.at

* Correspondence: antje.potthast@boku.ac.at

check for updates

Citation: Bausch, F.; Owusu, D.D.; Jusner, P.; Rosado, M.J.; Rencoret, J.; Rosner, S.; del Río, J.C.; Rosenau, T.; Potthast, A. Lignin Quantification of Papyri by TGA-Not a Good Idea. Molecules 2021, 26, 4384. https:// doi.org/10.3390/molecules26144384

Academic Editor: Pedro Fardim

Received: 29 June 2021

Accepted: 19 July 2021

Published: 20 July 2021

Publisher's Note: MDPI stays neutral with regard to jurisdictional claims in published maps and institutional affiliations.

\begin{abstract}
Papyri belong to the oldest writing grounds in history. Their conservation is of the highest importance in preserving our cultural heritage, which is best achieved based on an extensive knowledge of the materials' constituents to choose a tailored conservation approach. Thermogravimetric Analysis (TGA) has been widely employed to quantify cellulose and lignin in papyrus sheets, yielding reported lignin contents of $25 \%$ to $40 \%$. In this work, the TGA method conventionally used for papyrus samples was repeated and compared to other lignin determination approaches (Klason-lignin and acetyl bromide-soluble lignin). TGA can lead to a large overestimation of the lignin content of commercial papyrus sheets $(\sim 27 \%)$ compared to the other methods $(\sim 5 \%)$. A similar overestimation of the lignin content was found for the pith and rind of the native papyrus plant. We concluded that the TGA method should, therefore, not be used for lignin quantification.
\end{abstract}

Keywords: papyrus; lignin; quantification; TGA; DTG; Klason-lignin; ABSL; conservation

\section{Introduction}

In the context of the preservation of valuable historical objects from plant sources, such as paper, garments, furniture, or tapestry, a proper understanding of the ratio of the main constituents—cellulose, hemicelluloses, and lignin—is crucial to assess the status of conservation and to recommend suitable conservation treatments. A particularly illustrative example demonstrating this necessity is the Viking Ships in the Oseberg collection: a treatment with alum about 100 years ago led to an almost complete acidic degradation of the polysaccharide constituents, leaving the conservators no other choice than to try to preserve at least the remnants of conservation agents and lignin [1]. Another case is the Annals of the Joseong Dynasty, a thousand-year account of court life in Ancient Korea and the longest continuously written report in history. Attempts to stabilize the aging, brittle material with beeswax were of only short-lived benefit: mold that fed on the wax's triglycerides decomposed the "preserved" papers much faster than the untreated ones [2].

Material analysis of ancient papyri started comparatively early, at the latest in 1821, when Humphry Davy reported a series of analyses on papyri from Herculaneum, including pyrolysis and slow combustion - a predecessor, if you will, to modern TGA, but in any case, a means to determine the ash content (5\% to $6 \%$ ) [3].

One of the first and potentially most influential lignin quantifications for modern and ancient papyrus sheets was published by Wiedemann and Bayer in 1983, based on thermogravimetric analysis (TGA), see Table 1. This approach has often been repeated, 
cited, and discussed rather uncritically [4-7]. The reported lignin content of $22 \%$ to $32 \%$ percent has ever since shaped the conception of conservators and conservation scientists about the lignin content of papyrus, see Table 1. Papers with a similar lignin content were even chosen as model substrates for an accelerated aging study, because it was assumed that this material composition resembled that of papyri [8].

Table 1. Comparison of lignin content of papyrus sheets (or stems) reported in the literature.

\begin{tabular}{cccc}
\hline Lignin Content & Method & Reference & Ash Content \\
\hline $22-32 \%$ & TGA & {$[4]$} & $2-14 \%$ \\
\hline $32-40 \%$ & TGA & {$[9]$} & Subtracted \\
\hline $22-26 \%$ & TGA & {$[10]$} & $\sim 20 \%$ \\
\hline $36-40 \%$ & unspecified & {$[11]$} & Not determined \\
\hline $29-47 \%$ & Py-GC/MS & {$[12]$} & Not subtracted \\
\hline $13 \%$ & “a TAPPI method" & {$[13]$} & Not determined \\
\hline $12-25 \%$ & Klason & {$[14]$} & $6 \%$ \\
\hline $17 \%$ & Klason & {$[15]$} & $3 \%$ \\
\hline $14 \%($ whole stem) & ABSL & {$[16]$} & Not determined \\
\hline
\end{tabular}

The results in Table 1 present large differences with regard to lignin content, depending on the method used. While Klason Lignin and ABSL yielded values mostly around $15 \%$ lignin content, TGA-quantification results gave double the lignin content or even more. Lucejko et al. [12] outnumbered even these values for the lignin content of fresh papyrus plants ("middle of the stem"), reporting 46.9\% lignin, determined by Pyrolysis-Gas Chromatography/Mass Spectrometry (Py-GC/MS). For modern papyrus sheets, they reported a lignin content of $29 \%$. For their calculation, the peaks found in the chromatograms were assigned either to cellulose or to lignin. The contributions of hemicellulose, extractives, or inorganic matter were not taken into consideration regarding the total weight of the sample, hence, lignin (and cellulose) contents were increased compared to other methods.

Lignin quantification by TGA has been particularly appreciated by conservation scientists due to its low sample demand of below $10 \mathrm{mg}$, as opposed to up to $10 \mathrm{~g}$ for Klason lignin determination according to the TAPPI standard for pulp [17], which determines the lignin contents after acidic degradation of the polysaccharides. Such sample requirements are clearly not feasible for historical specimens, especially in the case of valuable objects. Another lignin determination approach, known as the ABSL (acetyl bromide soluble lignin) method $[18,19]$, is based on derivatization and solubilization of the lignin and subsequent determination by UV/Vis spectroscopy (absorption band at $280 \mathrm{~nm}$ ). Although this approach is similarly economical to TGA in terms of sample requirements, it has never been applied in papyrus conservation studies.

In this study, lignin quantification of papyrus samples was addressed. The TGAquantification approach was repeated and studied in detail. The results were compared to the values obtained by the Klason lignin and ABSL methods. According to ancient sources, papyrus sheets should almost completely consist of papyrus pith [20], but more recent literature is not always clear about which parts of the papyrus stem had been used in their analytical studies [16]. Therefore, also papyrus rind was included in the study, along with papyrus pith and commercial sheets, both from Qaramos, Egypt.

Figure 1 depicts the sample material used in this study. Rind was removed using a razor blade or a nylon thread. Rind and pith were dried, as shown for native pith in Figure 1b. The final product of contemporary Egyptian papyrus sheet manufacture, shown in Figure 1c, was analyzed as well, although one might expect the final sheet to have the same lignin content as native pith, since historic sources indicate no production step that would cause significant lignin removal [21]. 
a)

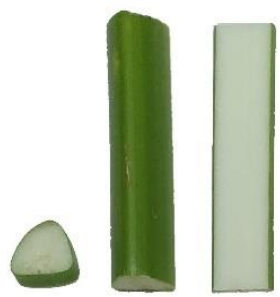

b)

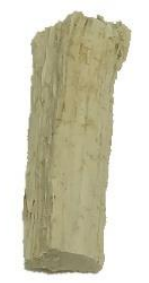

c)

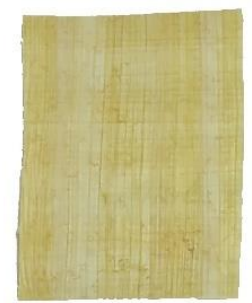

Figure 1. (a) Freshly cut papyrus stems in cross-section, part of a stem, and the stem cut in a longitudinal direction, as it is done for papyrus sheet production. (b) Dried papyrus pith, after the removal of the green rind. (c) A commercial papyrus sheet.

\section{Results and Discussion}

\subsection{Re-Evaluation of TGA-Literature Values and Comparison to Reference Materials}

In order to examine how the literature values had been obtained, the TGA parameters of Wiedemann and Bayer were re-applied. Samples of papyrus sheets, pith, and rind of the papyrus plant, were heated up to $100{ }^{\circ} \mathrm{C}$ in an oxygen atmosphere and, for comparison, in an inert nitrogen atmosphere (Figure $2 \mathrm{a}, \mathrm{c}$ ) at a heating rate of $10 \mathrm{~K} / \mathrm{min}$. The weight loss was recorded. To study the behavior of the individual components of papyri, the same conditions were applied to pure cellulose (Whatman filter paper No.1), hemicellulose (xylan), and papyrus lignin, extracted as "milled wood" lignin preparations (MWL) of Cyperus papyrus L. pith, according to [22,23] (Figure 2b,d).

a)

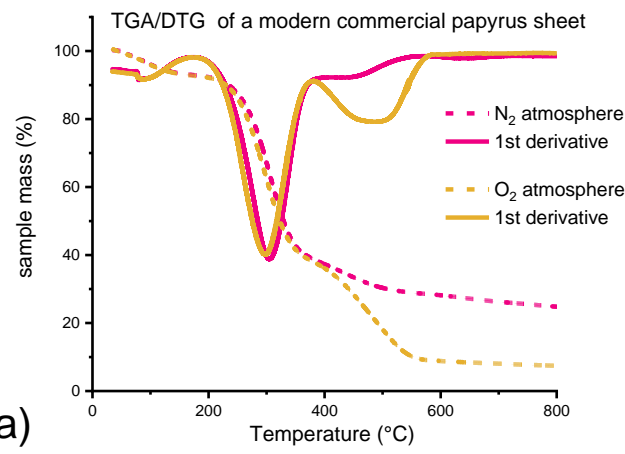

TGA/DTG curves for papyrus pith and a commercial papyrus sheet

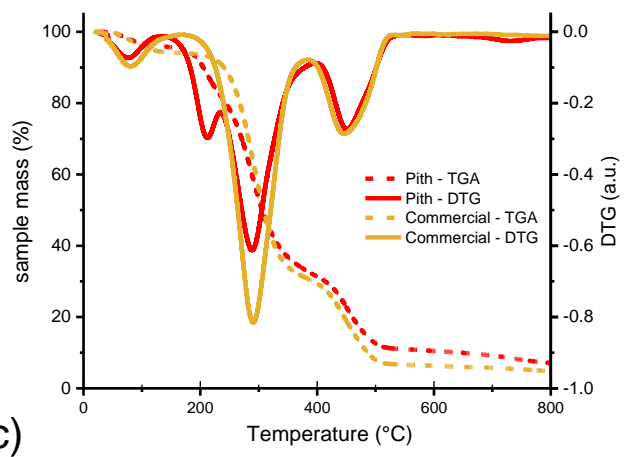

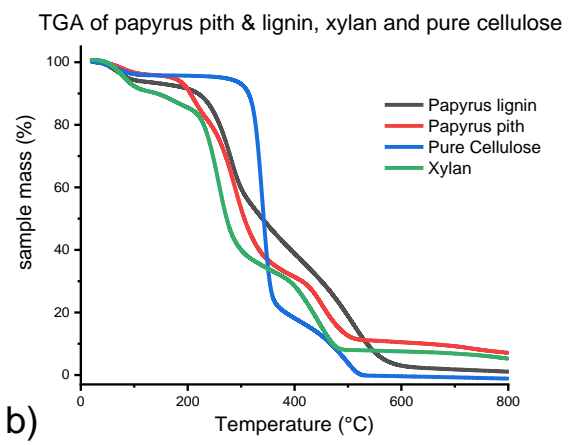

DTG-curves for papyrus pith \& lignin, xylan and cellulose

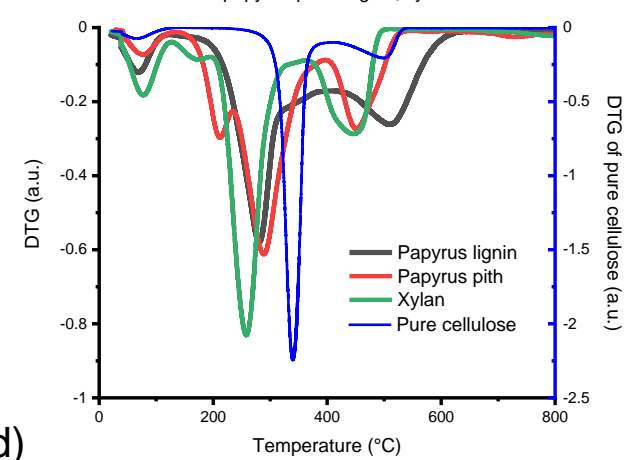

Figure 2. (a) Thermogravimetry (TGA) and derivative thermogravimetry (DTG) curves for a commercial papyrus sheet sample in nitrogen and oxygen atmosphere; (b) TGA curves (oxygen atmosphere) for papyrus lignin, papyrus pith, pure cellulose (Whatman filter paper No. 1), and a xylan sample. (c) TGA/DTG curves (oxygen atmosphere) for native papyrus pith and a commercial papyrus sheet (obtained one year later from the same supplier as the sample in (a)). (d) DTG curves (oxygen atmosphere) for papyrus lignin, papyrus pith, xylan, and pure cellulose (blue). DTG for pure cellulose is depicted on the right $Y$-axis (blue, different scale). 
The TGA curve shapes reported in the literature (Wiedemann and Bayer, 1983) for measurement in oxygen atmosphere were confirmed (Figure 2a). Thermal degradation of papyrus samples, after initial water removal above $100{ }^{\circ} \mathrm{C}$, reached a maximum at $300^{\circ} \mathrm{C}$ in a defined step, which became better observable as a distinct minimum in the firstderivative plot of the degradation curve (derivative thermogravimetry, DTG). In an oxygen atmosphere, there is a second distinct minimum around $500{ }^{\circ} \mathrm{C}$, which is largely reduced for measurements under nitrogen (Figure 2a). In the literature cited in Table 1 [4,9-11], the first minimum at $300{ }^{\circ} \mathrm{C}$ was assigned to cellulose, the second minimum at about $500{ }^{\circ} \mathrm{C}$ to lignin. Quantification was done by integrating the respective peaks in the DTG plot.

As is evident from the degradation curves of the individual components (Figure 2b), there is no clear step attributable to lignin degradation. Papyrus lignin shows a degradation pattern that is to some extent similar to that of papyrus pith in the lower temperature range with a minimum around $270{ }^{\circ} \mathrm{C}$ in the DTG-plot (Figure 2d). At higher temperatures, it exhibits a very broad, gradual degradation curve, whereas cellulose degradation is characterized by a rather steep and sharp degradation step around $350{ }^{\circ} \mathrm{C}$ (Figure $2 \mathrm{~b}, \mathrm{~d}$ ). The second region of slower degradation of lignocellulosic materials, between 350 and $500{ }^{\circ} \mathrm{C}$, gives rise to a second, broader minimum around $480{ }^{\circ} \mathrm{C}$ in the first derivative. This minimum has been wrongly assigned to lignin in previous literature (compare Table 1 ). It originates from further oxidation of dehydration, degradation, and condensation products of cellulose and hemicelluloses, which are usually denoted as humins. These compounds, mostly ladder-type oligomers with mixed furanoid and benzoid moieties [24], are typical products of pyrolytic and also acid-catalyzed processes of pyranoses and furanoses. They degrade more slowly in oxygen than the initial cellulose and give rise to stable graphenoid residues in the absence of oxygen. The second minimum is much larger in an oxygen atmosphere (Figure 2a), which means that a huge fraction of the mass content quantified as lignin in the literature arises from combustion processes, which are not taking place in an inert atmosphere. This additional mass loss for combustion processes as compared to pyrolysis in an inert atmosphere is found for cellulose, hemicelluloses, and lignin in a similar fashion [25]. The degradation curve for papyrus is, therefore, a superposition of the individual curves from lignin and cellulose/hemicelluloses, with the graph of the former being rather broad and the graphs of the latter two being steeper (Figure 2d). The less steep shape of the curve of papyrus pith as compared to the commercial papyrus sheet sample may indicate indirectly that the sheet has a somewhat lower lignin content (resulting in a steeper curve) than the original pith. Degradation starts at lower temperatures for papyrus pith and papyrus lignin (Figure 2b), as opposed to pure cellulose, which suggests that the first region of thermal degradation of papyrus pith is caused by the contained lignin. However, this region can never serve as basis to quantify the entire lignin content, since lignin degrades in a very broad region, e.g., for papyrus lignin between 250 and $600{ }^{\circ} \mathrm{C}$. The same alleged "lignin peak" as in native papyrus pith is obtained by combusting xylan, also with minor contributions from cellulose (Figure 2d). This illustrates clearly the faultiness of the previous assignment and, moreover, that the approach of just assigning a small area in the TGA/DTG curves solely to lignin will lead to wrong results.

\subsection{Comparison to Other Methods of Lignin Determination (Klason-Lignin and ABSL)}

To correct the lignin contents reported by the TGA approach and to check whether they range at least in a reasonable order of magnitude, we turned to alternative methods to determine lignin contents, namely the Klason lignin method (residue after carbohydrate solubilization in $72 \%$ sulfuric acid) and the acetyl bromide method (ABSL, UV absorbance at $280 \mathrm{~nm}$ from lignin phenols after complete derivatizing solubilization of the sample in acetyl bromide) for more precise values. In contrast to the gravimetric methods (TGA and Klason lignin) the ABSL approach makes use of a specific property of lignin, its UV absorption, to quantify it directly.

As clearly shown in Figure 3, the TGA-quantification approach always led to an over-estimation regarding lignin content. This became especially drastic for the commer- 
cial papyrus sheet, where the TGA results gave a lignin content five times higher than according to the alternative methods. Klason-Lignin and ABSL provided quite consistent values throughout.

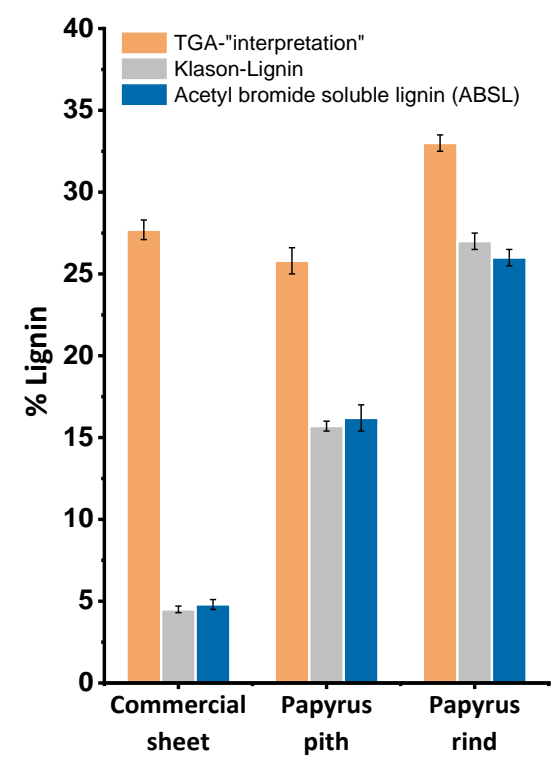

Figure 3. Lignin contents of a commercial papyrus sheet, native pith, and native rind, determined by TGA as compared to Klason-Lignin and acetyl bromide soluble lignin (ABSL).

Comparing the approach of lignin quantification by TGA, as applied in the literature, to more commonly used methods of lignin quantification in the pulp and paper industry, two things become obvious. First, other substances, such as hemicelluloses, can wrongly contribute to the lignin content (Figure 2d), and second, this is not just a theoretical problem, as the lignin values of papyri reported by TGA "quantification" are far too high. Native papyrus pith contains only around $16 \%$ lignin, as opposed to $25 \%$ up to $47 \%$ following the literature. Lignin contents of commercial papyrus sheets determined according to Klason lignin and ABSL methods were, to our surprise, significantly lower than those of native pith, while rather similar contents were expected if the papyrus sheets had been produced according to ancient recipes. This huge difference was obviously not found using the TGA approach, where the curve minimum previously and wrongly used for lignin quantification shows a very similar peak area for commercial papyrus sheets and native papyrus pith (Figures $2 \mathrm{c}$ and 3). Possible reasons for the huge decrease in lignin content when producing contemporary commercial papyri from papyrus pith will be described in a detailed upcoming account. The very low lignin content of around $5 \%$ in commercial sheets has severe implications with regard to conservation decisions, or when an appropriate material for facsimilia of ancient papyri is to be manufactured, especially if a lignin content of up to $50 \%$ is assumed based on [12].

\subsection{General Discussion of Lignin Abundance in Papyrus Pith by Microscopic/Staining Analysis}

Two general ideas regarding optical and structural properties of papyrus pith support the finding that lignin content in papyrus pith is much lower than in previous claims. Lignin is the "usual suspect" to color lignocellulosic materials brown, but native papyrus pith is white (compare Figure 1). The pith mainly consists of a ground tissue of parenchyma cells with big intercellular spaces, called aerenchyma, which is typical for aquatic plants (Figure $4 \mathrm{~b}$ ). Within the aerenchyma, several vascular bundles can be found. Structurally, lignin in papyrus stems is mainly found in the sclerenchymatous tissue of the vascular bundles. This lignified tissue strengthens the vascular bundles, which enable the transport of water, nutrients, and carbohydrates in the papyrus stem. The sclerenchyma can be colored bright red with the Safranin-O dye (Figure 4a). As seen in Figure 4a, a lot more 
lignified tissue is found in the rind, which explains the different values of lignin content between rind and pith. The rind consists of the epidermis, the sclerenchymatous hypodermis, and the cortical chlorenchyma, which results in its green color (Figure 1). The number of vascular bundles in/next to the chlorenchyma is higher but their size is smaller than that of those occurring within the aerenchyma of the pith. Thus, in the rind, lignified cell walls are found not only in the more numerous vascular bundles, but also in the sclerenchyma cells of the hypodermis.

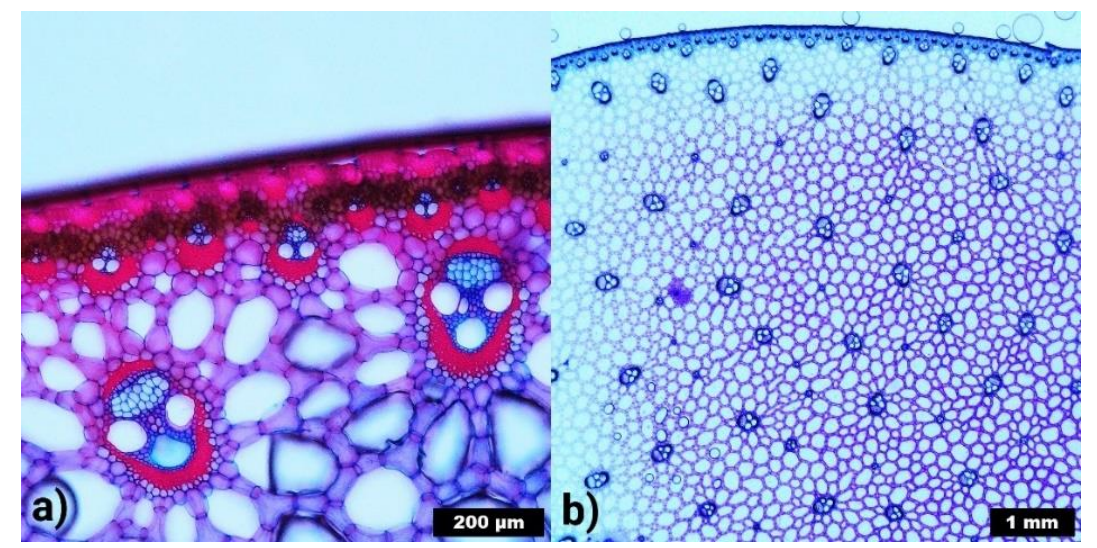

Figure 4. Microscopic images of cross-sections of Cyperus papyrus L. stems. (a) Detail of the outer region of papyrus pith. Lignified areas are colored red with Safranin-O, cellulosic areas are stained with Astra Blue and appear blue/pink. Scale bar $200 \mu \mathrm{m}$. (b) Overview of the structure of papyrus pith, stained with toluidine. The denser vascular bundles appear darker. Scale bar $1 \mathrm{~mm}$.

Figure $4 \mathrm{~b}$ provides an overview of the structure of a papyrus stem in cross-section. It becomes clear that vascular bundles, despite being a most important and integral constituent of papyrus pith, do not appear in an abundance that could suggest a lignin content of up to $50 \%$ in the pith. Values around $16 \%$ seem more reasonable, especially when considering that the vascular bundles are not solely composed of lignified sclerenchymatous tissue.

\section{Conclusions and Outlook}

A previous TGA-based approach to quantify lignin in papyrus material, originating from 1983 and frequently used and cited since then, provides wrong results. It attempted to quantify lignin from DTG curves by a peak that originated from polysaccharides, or, more precisely, from the combustion of primary pyrolysis products of polysaccharides. This led to a severe over-estimation of the lignin content. While the literature contents up to $50 \%$ were far too high, values around $5 \%$ for commercial papyrus sheets and $16 \%$ for native papyrus pith were obtained by two alternative and well-matching lignin determination methods, the Klason-lignin and the acetyl bromide soluble lignin (ABSL) methods. These methods gave reproducible and reliable lignin contents for papyrus sheets as well as the pith and rind of the papyrus plant. The ABSL method is recommended for further research as it has a sample demand similarly small to TGA, which is an important issue in the field of conservation research. The use of IR spectroscopy [26] which is completely non-destructive and proved to be helpful in fast compositional analyses of bioproducts, is currently studied for the papyrus case. An upcoming study will also address the gap in lignin content between commercial papyrus sheets and native papyrus pith, as a consequence of modernday deviations from the traditional historic procedure of papyrus manufacture.

\section{Materials and Methods}

\subsection{Materials}

Cyperus papyrus L. stems were acquired directly from farmers in Qaramos, Sharquia Province, Egypt. Rind was removed by slicing the fresh papyrus stems with a nylon fiber, 
rind and pith were subsequently air-dried for one week. Commercial papyrus sheets were obtained from farmers in the same village.

Whatman Filter paper was obtained from Sigma-Aldrich, Steinheim, Germany. Xylan was obtained from Lenzing AG, Lenzing, Austria.

Safranin-O, Astra Blue, and Toluidine were obtained from Merck KGaA, Darmstadt, Germany.

All chemicals were purchased at the best quality available.

\section{2. "Milled Wood" Lignin (MWL) Isolation from Papyrus Pith}

To obtain papyrus lignin, air-dried Cyperus papyrus L. pith was milled using an Ultra Centrifugal Mill ZM 200 (Retsch, Haan, Germany). Extractives were removed by Soxhlet extraction, with acetone (12 h), methanol (16 h), and hot water (12 h) as the solvents. Lignin isolation was conducted according to the standard procedure [22]. The pre-extracted papyrus pith samples were finely milled in a PM100 planetary ball mill (Retsch, Haan, Germany) for $5 \mathrm{~h}$ at $400 \mathrm{rpm}$ in a $500 \mathrm{~mL}$ agate jar and agate ball bearings $(20 \times 20 \mathrm{~mm})$. Lignin isolation was conducted using dioxane-water $(90: 10, v / v)$ for $3 \times 12 \mathrm{~h}$. The crude MWL preparation was purified as described in detail in [23]. The yield of the isolated MWL preparation was approx. $20 \%$ of the Klason lignin content of papyrus pith.

\subsection{Lignin Content Determination by Acetyl Bromide Derivatization and UV-Detection}

Commercial papyrus sheets, and native papyrus pith and rind from Egypt were milled using an Ultra Centrifugal Mill ZM 200 (Retsch, Haan, Germany). Extractives were removed by accelerated solvent extraction (ASE) on an ASE 350 (Dionex, Sunnyvale, USA), based on a literature protocol [27]. Conditions were $60^{\circ} \mathrm{C}, 11 \mathrm{MPa}, 15 \mathrm{~min}$ static time, $36 \mathrm{~mL}$ per cycle. The samples were extracted by two cycles of hexane and four to six subsequent cycles of acetone/water (95:5) until the filtrate was colorless.

All samples were dried for three days in a vacuum dryer (Goldbrunn 1450, Berlin, Germany) at $40{ }^{\circ} \mathrm{C}$. The samples ( 2 to $5 \mathrm{mg}$ in triplicates) were dissolved in a mixture of $25 \%(v / v)$ acetyl bromide in glacial acetic acid $(0.2 \mathrm{~mL})$, heated to $50{ }^{\circ} \mathrm{C}$, and stirred for $2 \mathrm{~h}$, based on [18]. The dissolved samples were added to a mixture of aqueous $\mathrm{NaOH}$ $(1 \mathrm{~mL}, 2 \mathrm{M})$ and hydroxylamine hydrochloride $(0.175 \mathrm{~mL}, 0.5 \mathrm{M})$, and the volume was adjusted to $10 \mathrm{~mL}$ by glacial acetic acid. Absorbance was measured at $280 \mathrm{~nm}$ on a Perkin Elmer Lambda 35 UV/Vis Spectrometer (Waltham, MA, USA). An extinction coefficient of $20 \mathrm{~L} / \mathrm{g}^{*} \mathrm{~cm}$ was applied [16] to calculate the amount of acetyl bromide-soluble lignin.

\subsection{Determination of the Lignin Content by the Klason Method}

The Klason lignin content was estimated as the residue after sulfuric acid hydrolysis of $300 \mathrm{mg}$ of pre-extracted material (after sequential Soxhlet extraction with acetone, $12 \mathrm{~h}$, methanol, $24 \mathrm{~h}$, and hot water, $12 \mathrm{~h}$ ), according to TAPPI T222 om-88 [17] and corrected for ash and protein content as previously published [23]. The acid-soluble lignin was determined, after the insoluble lignin was filtered off, by UV-spectroscopy at $205 \mathrm{~nm}$ according to [17], using $110 \mathrm{~L} \mathrm{~cm}^{-1} \mathrm{~g}^{-1}$ as the extinction coefficient. Three replicates were measured for each determination. The values displayed in Figure 3 express the sum of Klason-lignin and acid-soluble lignin.

\subsection{Thermogravimetric Analysis}

Thermogravimetric analysis was conducted on a TG 209 F1 Thermo-Microbalance (Netzsch, Selb, Germany). The dry sample material (5 to $15 \mathrm{mg}$ ) was heated up to $1000{ }^{\circ} \mathrm{C}$ in aluminum oxide crucibles at a rate of $10 \mathrm{~K} / \mathrm{min}$, measurements were done in triplicate. All samples were heated in an oxidizing atmosphere $\left(\mathrm{N}_{2}: \mathrm{O}_{2} / 4: 1\right)$ of $20 \mathrm{~mL} / \mathrm{min}$ and protective flow of $8 \mathrm{~mL} / \mathrm{min}$, except for the commercial papyrus sheet in Figure 2a. For the measurements in Figure 2a, the same oxidizing conditions as for the other samples were compared to an inert atmosphere applying $20 \mathrm{~mL} / \mathrm{min} N_{2}$ flow and $8 \mathrm{~mL} / \mathrm{min} N_{2}$ protective flow. The Proteus software was used for data evaluation and manipulation. 


\subsection{Microscopic Analysis}

Microscopic analysis of Cyperus papyrus L. stems was conducted with an Olympus DX 1000 digital microscope in incident light mode. For magnification in Figure 4a, the objective lens XLOB 20× with an objective magnification of $20 \times$ was used, for magnification in Figure $4 \mathrm{~b}$, the objective lens XLOB $3 \times$ with an objective magnification of $3 \times$. Cross-sections were cut with a razor blade. The native tissue was stained with Astra Blue for cellulosic tissue and Safranin-O for lignified tissue. Toluidine was applied to enhance the contrast of the entire sample.

Author Contributions: F.B., T.R., J.C.d.R. and A.P. conceptualized the study, F.B., D.D.O., M.J.R., J.R. and S.R. conducted the measurements. P.J. conducted data curation. F.B. wrote the initial draft, A.P., J.C.d.R. and T.R. reviewed and edited the paper. All authors have read and agreed to the published version of the manuscript.

Funding: Funding by the Austrian Biorefinery Center Tulln (ABCT) and the County of Lower Austria is greatly acknowledged. J.C.d.R., J.R. and M.J.R were funded by the Spanish State Research Agency and the European Regional Development Fund (project AGL2017-83036-R), and by the Junta de Andalucía (project P20-00017).

Data Availability Statement: Not applicable.

Acknowledgments: We thank Karin Baumgartner and Karin Hage-Ahmed from the Institute of Plant Protection, BOKU, for botanical advice and support in growing papyrus plants. We thank Susanne Scheffknecht, Institute for Botany, BOKU, for support in staining and microscopy. We appreciate the help of Claudia Gusenbauer and Ivana Czabany from the Institute of Wood Technology and Renewable Materials, BOKU, for their kind support and for providing access to their microscope and thermogravimetric analysis facilities. We thank Anna-Maria Stefanescu and Serban Herlea for help with the graphical design.

Conflicts of Interest: The authors declare no conflict of interest.

Sample Availability: Not applicable.

\section{References}

1. Braovac, S.; McQueen, C.M.A.; Sahlstedt, M.; Kutzke, H.; Łucejko, J.J.; Klokkernes, T. Navigating Conservation Strategies: Linking Material Research on Alum-Treated Wood from the Oseberg Collection to Conservation Decisions. Herit. Sci. 2018,6 , 77. [CrossRef]

2. Jeong, M.J.; Bogolitsyna, A.; Jo, B.M.; Kang, K.Y.; Rosenau, T.; Potthast, A. Deterioration of Ancient Korean Paper (Hanji), Treated with Beeswax: A Mechanistic Study. Carbohydr. Polym. 2014, 101, 1249-1254. [CrossRef] [PubMed]

3. Davy, H. XV. Some Observations and Experiments on the Papyri Found in the Ruins of Herculaneum. Philos. Trans. R. Soc. Lond. 1821, 111, 191-208. [CrossRef]

4. Wiedemann, H.G.; Bayer, G. Papyrus: The Paper of Ancient Egypt. Anal. Chem. 1983, 55, 1220-1230. [CrossRef]

5. Franceschi, E. Thermoanalytical Methods: A Valuable Tool for Art and Archaeology. J. Therm. Anal. Calorim. 2011, 104, 527-539. [CrossRef]

6. Basile, C. I Papiri Carbonizzati Di Ercolano La Temperatura Dei Materiali Vulcanici E Le Tecniche Di Manifattura Dei Rotoli; Associazione Istituto internazionale del papiro: Siracusa, Italy, 1994.

7. Nielsen, I. PAPYRUS Structure, Manufacture and Deterioration. Ph.D. Thesis, School of Conservation, Copenhagen, Denmark, 1985.

8. $\quad$ Łojewska, J.; Rabin, I.; Pawcenis, D.; Bagniuk, J.; Aksamit-Koperska, M.A.; Sitarz, M.; Missori, M.; Krutzsch, M. Recognizing Ancient Papyri by a Combination of Spectroscopic, Diffractional and Chromatographic Analytical Tools. Sci. Rep. 2017, 7, 1-12. [CrossRef]

9. Flieder, F.; Delange, E.; Duval, A.; Leroy, M. Papyrus: The Need for Analysis. Restaur. Int. J. Preserv. Libr. Arch. Mater. 2001, 22, 84-106.

10. Franceschi, E.; Luciano, G.; Carosi, F.; Cornara, L.; Montanari, C. Thermal and Microscope Analysis as a Tool in the Characterisation of Ancient Papyri. Thermochim. Acta 2004, 418, 39-45. [CrossRef]

11. Maggen, M. The Conservation of Papyri Documents Dated to the 4th Century BCE. Restaur. Int. J. Preserv. Libr. Arch. Mater. 1997, 18, 153-161. [CrossRef]

12. Lucejko, J.J.; Colombini, M.P.; Ribechini, E. Chemical Alteration Patterns of Ancient Egyptian Papyri Studied by Pyrolysis-GC/MS with in Situ Silylation. J. Anal. Appl. Pyrolysis 2020, 152, 104967. [CrossRef]

13. McGovern, J.N. Bonding in papyrus and papyrus-like mats. TAPPI 1982, 65, 159-162. 
14. El Meligy, M.G.; Wahba, W.N. True Paper from Papyrus. Restaur. Int. J. Preserv. Libr. Arch. Mater. 2002, 23, 27-38. [CrossRef]

15. El Ashry, E.H.E.; El Kilany, Y.; El Engebawy, A.; El Taraboulsi, M.A. Some Chemical Data on Cyperus Papyrus, L. the Ancient Papermaking Material. Egypt. J. Chem. 2003, 46, 181-185.

16. Karlen, S.D.; Free, H.C.A.; Padmakshan, D.; Smith, B.G.; Ralph, J.; Harris, P.J. Commelinid Monocotyledon Lignins Are Acylated by P-Coumarate. Plant. Physiol. 2018, 177, 513-521. [CrossRef] [PubMed]

17. TAPPI T 222 Om-88. 2004.

18. Fukushima, R.S.; Hatfield, R.D. Extraction and Isolation of Lignin for Utilization as a Standard to Determine Lignin Concentration Using the Acetyl Bromide Spectrophotometric Method. J. Agric. Food Chem. 2001, 49, 3133-3139. [CrossRef] [PubMed]

19. Hatfield, R.D.; Grabber, J.; Ralph, J.; Brei, K. Using the Acetyl Bromide Assay To Determine Lignin Concentrations in Herbaceous Plants: Some Cautionary Notes. J. Agric. Food Chem. 1999, 47, 628-632. [CrossRef]

20. Leach, B. Papyrus Manufacture. UCLA Encycl. Egyptol. 2009, 1, 2.

21. Nicholson, P.T.; Shaw, I.; Press, C.U. Ancient Egyptian Materials and Technology; Cambridge University Press: New York, NY, USA, 2000; ISBN 978-0-521-45257-1.

22. Björkman, A. Studies on Finely Divided Wood. Part 1. Extraction of Lignin with Neutral Solvents. Sven. Papp. 1956, 59, 477-485.

23. Del Río, J.C.; Prinsen, P.; Rencoret, J.; Nieto, L.; Jiménez-Barbero, J.; Ralph, J.; Martínez, Á.T.; Gutiérrez, A. Structural Characterization of the Lignin in the Cortex and Pith of Elephant Grass (Pennisetum purpureum) Stems. J. Agric. Food Chem. 2012, 60, 3619-3634. [CrossRef]

24. Rosenau, T.; Potthast, A.; Zwirchmayr, N.S.; Hettegger, H.; Plasser, F.; Hosoya, T.; Bacher, M.; Krainz, K.; Dietz, T. Chromophores from Hexeneuronic Acids: Identification of HexA-Derived Chromophores. Cellulose 2017, 24, 3671-3687. [CrossRef]

25. Cheng, K.; Winter, W.T.; Stipanovic, A.J. A Modulated-TGA Approach to the Kinetics of Lignocellulosic Biomass Pyrolysis/Combustion. Polym. Degrad. Stab. 2012, 97, 1606-1615. [CrossRef]

26. Hell, J.; Prückler, M.; Danner, L.; Henniges, U.; Apprich, S.; Rosenau, T.; Kneifel, W.; Böhmdorfer, S. A Comparison between Near-Infrared (NIR) and Mid-Infrared (ATR-FTIR) Spectroscopy for the Multivariate Determination of Compositional Properties in Wheat Bran Samples. Food Control 2016, 60, 365-369. [CrossRef]

27. Wilför, S.; Hemming, J.; Leppänen, A.S. Analysis of Extractives in Different Pulps-Method Development, Evaluation, and Recommendations; Report No. B1 of the EU COST E41 Action; Laboratory of Wood and Paper Chemistry: Turku, Finland, 2006. 